\title{
Progressive damage modeling in laminate composites under slamming impact water for naval applications
}

\author{
O. H. Hassoon ${ }^{1 \text { (a) }}$, M. Tarfaoui ${ }^{2 \text { (a) }}$, A. El Moumen ${ }^{3 \text { (a) }}$ \\ ${ }^{(a)}$ ENSTA Bretagne, IRDL, FRE CNRS 3744, F-29200 Brest, France
}

\begin{abstract}
The use of composite materials begin to normalize in various sectors, however, these structures are very susceptible to degradation of their properties and consequently a catastrophic failure. The response of deformable composite subjected to water-entry impact can cause a phenomenon called hydro-elastic effect due to water-flexible laminate interaction. This phenomenon may be large enough to cause the damage in composite panels. This paper employs the finite element method to simulate the behavior of composite wedges under slamming impact with presence of damage. To investigate this situation, the hydro-elastic influence has been analysis as both kinematic effect due to deflection of the composite panel and dynamic effect caused by the interaction between the water and the structure. On the other hand, damage modeling was formulated based on continuum damage mechanics for intra-laminar damage. A user-defined material subroutine VUMAT has been incorporated into explicit Abaqus FE software to enhance the damage simulation, which includes Hashin criteria for degradation of the panel stiffness with failure onset criteria and fracture mechanics. To reinforce the methodology adopted, numerical results are compared with the previous experimental data. A good agreement was observed. Effects of impact velocity and the panels flexibility on the damage have been investigated.
\end{abstract}

Keyword: Laminate composites, Impact behaviour, Damage mechanics, Finite element analysis, Slamming impact.

${ }^{1}$ Tel: +33668600885. E-mail address: omar_hashim.hassoon@ensta-bretagne.fr

${ }^{2}$ Tel:+33298348705. E-mail address: mostapha.tarfaoui@ensta-bretagne.fr

${ }^{3}$ Corresponding author. Tel: +33668600885. E-mail address: ahmed.el_moumen@ensta-bretagne.fr. 


\section{Introduction}

Composite materials have been used in the recent years in many industrial applications such as the aerospace, automobile and naval applications. This attention was primarily coming relative of their superior properties in terms of high strength, stiffness, lightweight and for their performance capability in critical practical application environment. In contrast, due to the complexity of the composite structure, a variety of the failure modes and damages are occurring compared with the metallic materials, which considered an active challenge area in the advanced material structure. For this reason, special attention requires in both design phase and operation phase, this done by incorporating the damage tolerance as a safety factors in the design loads $[1,2]$.

The damage mechanism in composite materials under slamming impact is importance to constrict the usage of composite materials in the naval application and assistant the designers to predict the critical locations in the structure [3]. Generally, researches have been constrained two modes for fibers. In the other hand, because the complexity of the matrix morphology; some of research studies have been incorporated more than one mode for matrix failure criteria. Various failure criteria models have been adapted to predict the damage onset based on a combination of the longitudinal, the transversal and the shear stresses $[4,5,6]$. One of the more satisfying criteria is based on the Hashin theory [5]. Tsai-Wu (1971) [6] have introduced a method that based on the maximum stress for transversely isotropic symmetry, which a one mode dominates the materials failure with seven parameters interacting with each other. Hence, it considered the simplest method for the damage onset. Hashin (1980) [4] was introduced a failure criteria for unidirectional fiber composites with second degree polynomial expansion. For more simplicity, he divided the failure status into four modes according to the failure plane that perpendicular and aligned to the fiber direction with six parameters, and on the other hand the main failure of the matrix in transverse direction. This criterion was widely applicable in the much commercial finite element software. However, some of authors said that this model not predict accuracy the initial failure, especially for matrix and fiber in compression modes [7]. Christensen (1998) [8] has proposed and has applied a criteria for failure under hydrostatic pressure. Therefore, reduced the parameters from 7 to 5 , and also reduced the failure mode to three applied condition (two modes for fiber and one mode for the matrix) that transverse tensile stress in tension is equal or less than the transverse compressive stress. Puck (2002) has developed the model represented by Hashin's criteria and based on Mohr's method applied to brittle fiber reinforcement composite. Nevertheless, this approach 
was taking into account the non-linearity behavior due to microcracks, matrix cracking and change in fiber directions. He incorporated the inter-fiber fracture (IFF) to detect many of the failure modes, and to define the planes acting on IFF. He believed that the inclination of the fracture plane parallel to the fiber is the main parameter, which will influence the onset of delamination.

Recently, many of the researches have been focused on composite damages under low and high velocity impact for the solid-solid interaction and concentrate on the interlaminar damage that happens in the sandwich and composite structure $[9,10,11,12]$. However, the slamming impact of the deformable structure, or composites, with the evaluation of the damage has been required hardly studied. This coming from experiment slamming observations that clarified the variation of the pressure peak distribution along the span panel can be occur, especially close to the chine. For this reason, this pressure creates high shear forces in this location. Parga-Landa et al. [13] have developed an analytical model based on the stress wave propagation to study the effect of the material properties on the delamination behavior in the ship panel under slamming impact. A parametric study has been achieved to investigate the stacking sequence and the strain effect of the interlaminar damage. They conclude that the stress components cannot be neglected in the strength and the fatigue loading, stacking sequence has an influence on the delamination and with no effect of the strain rate. Kaushik and Batra [14] studied the slamming impact for the hull structures using the Multi-materials Eulerian Lagrangian model build in LS-DYNA for both rigid and deformable structures. Their results indicate that the pressure of deformable panels differs from the plate theory and Wagner theory, and a high pressure occurs close to the panel edges due to the hydroelastic influence, which produces a high shear stress between the interface of the skin and the core in sandwich structure. Manganelli and Wilson [15] proposed an experimental study concerning the effects of slamming on offshore sailing yachts. Valuable data can be obtained by instrumenting structure boats directly. Santos et al. [16] studied the symmetric dynamic behavior for the fast patrol boat using the unified hydroelasticity analysis. They modeled the structure using beam and three finite element methods. Moreover, the coupling between the fluid-structure interactions was performed using 3D potential flow theory. Charca and Shafiq [17, 18] studied experimentally the slamming problem in the single and repeating slamming impact to assessment the damage in sandwich structures. They observed that the catastrophic failure occurs beyond the threshold strain 0.0035 with the signal slamming, a very little reduction in the flexural capacity has been occurs. In contract, 
the damage develops with more cycle repeating slamming, especially, face-core delamination and the local buckling of the faces as considered main damages dominate the structure response. Stenius et al. [19, 20, 21] used the experimental techniques and finite element based on the multi-material Arbitrary Lagrangian-Eulerian (ALE) formulation code for estimating the hydroelastic problem related to the panel-water impacts for high-speed craft. Experimentally, deflections and strains are compared with that corresponding to nonhydroelastic reference solutions. They indicate that the hydroelastic effects are located close to the panel supports for the very flexible panels and sandwich constructions. Xiao and Batra [22] have studied the water entry problem for composite sandwich structures based on the boundary element method to determine the fluid flow and the finite element method for both straight and curve deformable panels. Coupling between two models has been achieved with a third order shear and normal deformable plate/shell theory (TSNDT). The interlaminar damage (delamination) has been implemented using the cohesive zone model for both initiation and propagation.

This work focuses on slamming impact problem with presence of the damage for composite structures, which is implemented by incorporating a user-define material VUMAT into finite element method using Abaqus explicit code to investigate the intralaminar damage for fiber glass- vinylester reinforced laminate composite panels based on Hashin criterion. A comparison between numerical results and previous experimental data was achieved to validate the present model. Finally, the effect of such parameters namely; impact velocity, panels thickness and flexibility of the structures were studied.

\section{Constitutive progressive degradation of composite material}

Progressive failure models have been adopted in the finite element simulations to model the onset of damage and his propagation in composite materials based on the concept of the continuum damage mechanics (CDM). The material behavior can be characterized in two substantial phases namely the elastic and the failure regions. The elastic region means that the material can be come back to original shape dimensions without deformation when unloading. This phenomenon appears because the material have an elastic energy depended on material nature type. In the other hand, the second phase represents as post failure region, followed subsequent to the material satisfied the onset of the damage, and further loading results in a degradation of mechanical properties of the structure and subsequently to a reduction in its stiffness caused by the accumulation of cracks. The relationship between the effective stress $(\hat{\sigma})$ and nominal stress $(\sigma)$ can be defined in form: 


$$
\hat{\sigma}=d . \sigma
$$

Where $d$ is the damage operator

Thus stress with presence of the damages is given as:

$$
\sigma_{i, j}=C_{i, j}(d) \cdot \varepsilon_{i, j}
$$

where $C$ represents the undamaged orthotropic stiffness matrix. This matrix takes the following form:

$$
C=\left[\begin{array}{cccccc}
C_{11} & C_{12} & C_{13} & 0 & 0 & 0 \\
C_{12} & C_{22} & C_{23} & 0 & 0 & 0 \\
C_{13} & C_{23} & C_{33} & 0 & 0 & 0 \\
0 & 0 & 0 & C_{44} & 0 & 0 \\
0 & 0 & 0 & 0 & C_{55} & 0 \\
0 & 0 & 0 & 0 & 0 & C_{66}
\end{array}\right]
$$

Then the damage stiffness matrix as follow [23]:

$$
\begin{array}{ll}
d C_{11}=\left(1-d_{f}\right) E_{1}\left(1-v_{23}^{2}\right) \Gamma, & d C_{22}=\left(1-d_{f}\right)\left(1-d_{m}\right) E_{2}\left(1-v_{13}^{2}\right) \Gamma \\
d C_{33}=\left(1-d_{f}\right)\left(1-d_{m}\right) E_{3}\left(1-v_{21}^{2}\right) \Gamma, & d C_{12}=\left(1-d_{f}\right)\left(1-d_{m}\right) E_{1}\left(v_{21}-v_{31} v_{23}\right) \Gamma \\
d C_{23}=\left(1-d_{f}\right)\left(1-d_{m}\right) E_{2}\left(v_{32}-v_{12} v_{31}\right) \Gamma, & d C_{31}=\left(1-d_{f}\right)\left(1-d_{m}\right) E_{1}\left(v_{31}-v_{21} v_{32}\right) \Gamma \\
d C_{44}=\left(1-d_{f}\right)\left(1-d_{m t} s_{m t}\right) E_{1}\left(1-d_{m c} s_{m c}\right) G_{12}, & d C_{55}=\left(1-d_{f}\right)\left(1-d_{m t} s_{m t}\right) E_{1}\left(1-d_{m c} s_{m c}\right) G_{23} \\
d C_{66}=\left(1-d_{f}\right)\left(1-d_{m t} s_{m t}\right) E_{1}\left(1-d_{m c} s_{m c}\right) G_{31}, &
\end{array}
$$

where the damage variables and $\Gamma$ are given by equation 5 [23].

$$
\begin{gathered}
d_{f}=1-\left(1-d_{f t}\right)\left(1-d_{f c}\right) \\
d_{m}=1-\left(1-d_{m t}\right)\left(1-d_{m c}\right) \\
\Gamma=1 /\left(1-v_{12}{ }^{2}-v_{23}{ }^{2}-v_{13}{ }^{2}-2 v_{12} v_{23} v_{13}\right)
\end{gathered}
$$

where $d_{f}, d_{m}$ and $d_{s}$ is the damage variables for the fiber, matrix and shear failure mode respectively.

\subsection{Intralaminar failure criteria}

The laminate damage initiation is happening when the applied true stress in the laminate composite reaches the ultimate strength of the ply laminate. Explicitly, the debonding interface between the fiber and matrix occurs due to difference in the fiber transverse compressive modulus and the matrix modulus, which represents the main influence of damage initiation. A VUMAT subroutine in Abaqus explicit software was implemented, in the case of slamming impact, to characterize the intralaminar damage based on the Hashin failure criteria 
in the three dimensional form for fibers and matrix, which has been widely applied to predict the initiation of damage in a unidirectional composite $[4,24]$. In the present study, these criteria were proposed for both fibers and matrix, and listed in Table 1.

\subsection{Damage evolution}

As previously specified, after the initial failure criteria have been satisfied, and based on the relationship between the effective stress and displacement, the damage variable for each mode in fiber and matrix can be illustrated in form:

$$
d_{i}=\frac{\delta_{i, e q}^{f}\left(\delta_{i, e q}-\delta_{i, e q}^{0}\right)}{\delta_{i, e q}\left(\delta_{i, e q}^{f}-\delta_{i, e q}^{0}\right)} \quad, \delta_{i, e q}^{0} \leq \delta_{i, e q} \leq \delta_{i, e q}^{f}
$$

where $d_{i}$ is the damage variable defined for each damage mode. The variables $\delta_{e q}^{0}$, $\delta_{e q}$ and $\delta_{i, e q}^{f}$ represent respectively the initial displacement, equivalent displacement and equivalent failure displacement which are computed as follow:

$$
\begin{gathered}
G_{i}=\int_{\delta_{i, e q}^{0}}^{\delta_{i, e q}^{f}} \sigma d \varepsilon=\frac{1}{2}\left(\delta_{i, e q}^{f}-\delta_{i, e q}^{0}\right) \sigma_{i, e q}^{0} \\
\delta_{i, e q}^{f}-\delta_{i, e q}^{0}=\frac{2 G_{i}}{\sigma_{i, e q}^{0}} \\
\delta_{i, e q}^{0}=\delta_{i, e q} / \sqrt{f}_{i} \\
\sigma_{i, e q}^{0}=\sigma_{i, e q} / \sqrt{f}_{i}
\end{gathered}
$$

where $\sigma_{i, e q}, \sigma_{i, e q}^{0}, f_{i}$ and $G_{\mathrm{i}}$ are the equivalent stress, equivalent initial stress, initial failure and the fracture energy corresponding for each mode, respectively. These variables are computed at each element's integration point to describe the materials stiffness degradation. This scheme is shown in Fig. 1. 


\section{Model, specimens generating and meshing}

\subsection{Fluid domain characterization}

In slamming impact model, a fluid-structure interaction phenomenon requires to be solved simultaneously. Coupled Eulerian-Lagrangian Model (CEL) with Abaqus/Explicit, which can be used more than one materials model that couples the Lagrangian and Eulerian model. Volume of Fluid (VOF) method is capable to solve a wide range of non-linear problems in fluid and solid mechanics [25].

The equation of the state (EOS) can be describing by linear $U_{s}-U_{p}$ formulation of the Mie-Gruneisen equation of state, which can be exploited in water entry problem, and can be defined the pressure as a function of the density $(\rho)$ and the internal energy $\left(E_{m}\right)$ per unit mass as:

$$
\begin{gathered}
P=f\left(\rho, E_{m}\right) \\
U_{s}=C_{0}-s U_{p}
\end{gathered}
$$

where $U_{s}, U_{p}, C_{0}$ and $s=d U_{s} / d U_{p}$, are the linear shock velocity, particle velocity, the velocity of the sound in the fluid and linear Hugoniot slope coefficient, respectively.

Then the pressure of the fluid can be calculated as:

$$
P=\frac{\rho_{0} C_{0}{ }^{2} \mu}{(1-s \mu)^{2}}\left(1-\frac{\Gamma_{0} \mu}{2}\right)+\Gamma_{0} \rho_{0} E m
$$

where $\mu=1-\left(\rho_{0} / \rho\right)$ is the nominal volumetric compressive strain, $\rho_{0}$ is the initial density and $\Gamma_{0}$ is parameter of the approximation. Defined the water parameters in Table 2 with density of $1000 \mathrm{~kg} / \mathrm{m}^{3}$, the pressure of the fluid can be calculated as:

$$
P=\rho_{0} C_{0}^{2} \mu
$$

The fluid is considered as the Newtonian fluid flow, which means that the viscosity depends on the change of the temperature. The temperature is constant then the viscosity is also constant in this model. 


\subsection{Fluid-structure interaction algorithm}

The CEL formulation both the Eulerian and the Lagrangian equations of the model are depended on the same classical formulations of the conservation equations mass, energy and momentum. To couple the response of Eulerian and Lagrangian as the Lagrangian mesh moves in interface of the Eulerian mesh, both the Eulerian and Lagrangian occupied initial boundary conditions. Consequently, the coupling calculated by apply pressure boundary conditions on the Lagrangian mesh from the Eulerian mesh, while the Lagrangian mesh boundaries supplied velocity boundary conditions on the Eulerian mesh. Based on the Eulerian volume fraction (EVF), the Eulerian cell has assumes a constant pressure, since when it interacts with the Lagrangian the cell area will be change. The area centroid calculated by the Eulerian area that not intersects with Lagrangian and the reconstruction of pressure conditions. Thus, velocity conditions of the Lagrangian mesh are updated after calculation of the force from the Eulerian mesh. According to [26], the element volume is calculated by subtracting the Lagrangian volume from the volume of the Eulerian element. Once these quantities have been established, the stress and pressure are updated. The velocities of the uncovered parts of the element are updated in the normal manner. For more information concerning Abaqus CEL and a detailed description of the mathematical expressions, see $[27,28]$.

To prevent the Lagrangian body from overlap with the underlying Eulerian elements, the coupling force is calculated relative with the penetration rate based on the penalty coupling method, which working such as spring system attached in each of both node ends of the Lagrangian and Eulerian. The penalty coupling force is given as:

$$
F=k^{\prime} \cdot \mathrm{d}
$$

Where $k^{\prime}$ and $d$ representing the spring system stiffness and penetration respectively.

The spring stiffness is depended on the scaling factor, bulk modulus of the fluid and the mesh size of the fluid as descripted in equation (13):

$$
k^{\prime}=p_{f} \frac{K A}{v}
$$

Where $p_{f}, K, A$ and $v$ are respectively the penalty scale factor, the bulk modulus, the average area of the structure element and the volume of the fluid element, which are in the coupling state. 


\subsection{Stabilization and validation of model}

Before validating the numerical model developed with the tests carried out on semiflexible and flexible panels, we are interested here in the validation with results of the literature. The numerical model has compared and validated with experimental data found in $[20,29,30]$. The experimental test has performed using servo-hydraulic slam testing system (SSTS) to keep approximately the impact velocity as constant during the interested impact duration. Biaxial E-glass reinforced epoxy composite panel have considered in the present investigation to validate the numerical slamming model with VUMAT subroutine. The panel has simply supported along its edges, as shown in Fig. 2, and all panels have tested with $\beta=10^{\circ}$ deadrise angle. The boundary conditions, panel and water domain mesh have shown in Fig. 3. For more details about the SSTS machine, instrumentations and panel properties, see [20].

Fig. 4 and Fig. 5 show the comparison between the deformation in the center and close of chine panel for the numerical results and the experimental data for two different velocities impact: $V=2 \mathrm{~m} / \mathrm{s}$ and $V=4 \mathrm{~m} / \mathrm{s}$. It can be seen that the numerical results have been well predicted the panel deformation compared with experimental tests. A small discrepancy has observed in gauge deformation, which can be attributed to boundary conditions in the experimental setup. In other hand, the impact velocity is not really constant along the penetration time as in numerical model. Fig. 6 presents the comparison in the force between the experimental and numerical results in different velocities impact. A good agreement is also observed. For illustration, a snapshot of the model after impact test is presented in Fig. 7.

\subsection{Description of the fluid-Structure domain}

It should be noted that due to the symmetry of the water entry problem, the full $3 \mathrm{D}$ slamming model in Fig. 8.a is reduced to a 3D half model as described on Fig.9b. The simplification of the model leads to rapid convergence. The model consists of two different parts namely: solid part considered as an impactor and fluid domain considered as an impacted zone.

The exterior boundaries of Eulerian fluid domain are defined as non-reflecting boundaries to avoid reflection pressure waves, see Fig.9a. Water domain is divided in many regions as a result of high consuming calculation time of the model. Furthermore, it meshed with EC3D8R linear element Eulerian brick. The total mesh of slamming model was composed of 1078000 
cubic elements. This is clear that the mesh is refined close to the impact location between impactor and water surface and coarse at the extremes, Fig.9b.

In present study, two different composite panels have been study with dimensions of $(\mathrm{L}=495, \mathrm{~W}=250) \mathrm{mm}$ and fully clamped boundaries condition have been applied in the panel ends, as illustrated in Fig.9a. However, in order to incorporate the flexibility influence behavior with presence of the damage, glass-fiber vinylester composite panels with different stiffness: semi-flexible $(\mathrm{SF}) \mathrm{t}=13 \mathrm{~mm}$, flexible $(\mathrm{F}) \mathrm{t}=8 \mathrm{~mm}$, and the stacking sequence of [45/$45]_{9}$ and $[0 / 90]_{6}$ are considered and tested. In this work, all of the panels are examined with a deadrise angle of $\beta=10^{\circ}$ and the strain gauges (SG) and the pressure are located in the three different positions along the span panel to cover mode shapes natural frequency, see Fig. 10a. The positions of strain gauges were predicted from the mode natural frequencies of the dry panels using finite element code as shown in Fig. 10b. The details of the panel mechanical properties are listed in Table 3 [31].

\section{Numerical results: flexible and semi-flexible composite panels}

\subsection{Water-structure interaction}

The structure flexibility can change the water-structure boundary conditions due to the variation in the local deadrise angle and the fluid flow as shown in Fig. 11. In the case of flexible panels, Fig. 12 shows a high flexibility of the panel leading to increase these effects. This explains the reason behind a high pressure near to the chine due to change of a kinematic effect and loading of the fluid particles close to the interface.

Inertia effects are more appearance in high flexible structure response and increasing relatively with decrease the panel stiffness and increasing the impact velocity. For the high flexible panel with lower stiffness bending, it shows that a great structure deformation is occurred. However, the pressure close to the chine edge has very high amplitude and exceeds the pressure in the rigid body which implies that a high influence has been appeared which is illustrated in Fig. 13. This explains why some of the damage modes may be introduced.

\subsection{Dynamic response}

In order to analyze the panel response, the hydrodynamic force acts on the panel have been investigated with different impact velocities for flexible composite panel. It can be observed that the mechanical behavior of the damaged panel has changed compared to undamaged 
panel, as a result of evolution of the energy absorbed for propagation of matrix cracks. The hydrodynamic load and strain histories, plotted in Fig. 14, add a good understanding for the interpretation of the slamming behavior with different impact velocity. In every case, the initial stiffness of panels behaves the same response until initiation of the matrix cracks occurs. Increasing of the impact velocity leads to more stiffness degradation of the composite panel. In this case, the ultimate deflection of the panel exceeds the allowable value corresponding to Det Norske Veritas (DNV) classification societies [32]. In the present work for flexible panel, the deflection in the center of the panel equal to $18.6 \mathrm{~mm}$ that exceed the allowable deflection of $9.04 \mathrm{~mm}$.

\subsection{Damage assessment}

To demonstrate the capability of implemented subroutine for the intralaminar damage, model have been verified and tested in a sequence procedure to evaluate the validity of the results. For this reason, the model was tested in a single element with different loading conditions, consequently, given the authorization to apply it in the slamming impact simulation. The main damages in the composite laminate are the matrix damage in both tensile and compression modes. For the case of semi-flexible and flexible panels, the snapshot of damaged composite panels is presented in Fig. 15 and Fig. 16, respectively. However, damage has been raised relative to the increasing of impact velocity and the panel flexibility. Numerical predictions indicated that, for slamming impact, matrix damages localization initially occurred near to the edges of the panel (keel and chine) due to high peak pressure, as the results of changing in local deadrise angle and the local velocity of the fluid. An animation of the damage history of the composite panels under slamming impact is presented in attached Video 1 for flexible panels and Video 2 for semi-flexible panels.

Increasing the impact velocity can induce stress concentration in the panel center and close to the panel ends, see Fig. 17. In the other hand, matrix damage appears to be the first damage mode occurring in composite laminates under slamming impact loads, especially in the ends and center of panel, as illustrates in Fig. 18. This happens when the allowable deflection of the panel exceeds $2 \%$ of the shortest panel span and for the ultimate strain under single slamming impact $\approx 0.35 \%[33,17]$. The matrix tensile damage, quantifies in the top layers of the panel center, the keel and chine locations due to combination of the in-plan and through thickness stresses. Therefore, in the repeating slamming wave, cracks in the matrix begin to propagate in the direction of the fiber for different plies of the laminate composite and then 
bifurcated in inter-layer zones to create delamination. These cracks can cause rupture of fibers that leading to catastrophic failure.

Fig. 19 illustrates the variation of depth, or displacement of impactor (composite panels), and the formation of the fluid jet in the water domain under slamming test. It should be mentioned that the jet shows correct development and corresponds to slamming impact and non-surprising phenomenons were observed. For more illustration, Fig. 20 illustrates the damage history at different impact time. From these images, it appears that the damage is directly related to flexibility of composite panels. In most cases when impact has occurred, at same times, the damage has been minimal for semi-flexible panels compared to the case of flexible one (for example at $\mathrm{T}=6.525 \mathrm{~ms}$ ). We note also the formation of a pile-up region and water jet where the composite panel is completely submerged by water.

\section{Conclusions}

This paper presents a finite element analysis of the water entry problem for deformable wedge composite with the establishment of a subroutine for the consideration of the existence of damage. The study deals with the mechanical behavior and the identification of damage initiation and its development in dynamic tests. Two different stiffness panels, with $8 \mathrm{~mm}$ and $13 \mathrm{~mm}$, are used with different constant impact velocities; namely 6,8 and $10 \mathrm{~m} / \mathrm{s}$. Multimaterials Eulerian-Lagrangian model builds in finite element code (ABAQUS 14.6) was exploited to represent the water domain which more feasibility of modeling and allows high deformation in the fluid. The considered model was initially validated with experimental results in the literature. Kinematic effects along water-panel interface exhibited a larger elastic influence due to flexibility and the change in local deadrise angle. Consequently, these effects can be reducing the panel response which significantly appeared in higher velocity impact, especially in the center and the end of the panel. Based on the Continuum damage mechanics and fracture mechanics, a 3D damage model was formulated using user-materials routine VUMAT to enhance the damage simulation, and implemented into the finite element code. The more serious damage have been observed in the matrix close to the edges and in the center of the panel that assist ship designers to give more attention in these locations. The fiber damage needs more high impact energy to occur. The interlaminar damage for the sandwich panels is not addressed here and it will be the objective of the next investigation. The improved understanding of these phenomena and the development of predictive tools are part of an ongoing effort to improve the long-term integrity of composite structures for naval applications. 


\section{References}

[1] Zenkert D, Shipsha A, Bull P, Hayman B. Damage tolerance assessment of composite sandwich panels with localised damage. Composites Science and Technology 2005;65:2597-2611.

[2] Green E. Design guide for marine applications of composites. Ship Structure committee, Washington, 1997.

[3] Allen T. Mechanics of flexible composite hull panels subjected to water impacts. thesis, 2013.

[4] Hashin Z. Failure criteria for undirectional fiber composites. Journal of Applied Mechanics 1980;31:223-232.

[5] Hashin Z. Fatigue failure criteria for unidirectional fiber composites. Journal of Applied Mechanics 1981;48:846-852.

[6] Tsa S.W, Wu E. A general theory of strength for anisotorpic materials. Journal of Composite Materials 1971;5:58-80.

[7] Lapczyk I, Juan A. Hurtado. Progressive damage modeling in fiber-reinforced materials. Composites Part A: Applied science and manufacturing 2007;38:2333-2341.

[8] Christensen R. The numbers of elastic properties and failure parameters for fiber composites. Journal of Engineering Materials and Technology 1998;120:110-113.

[9] Tarfaoui M, Gning P, Hamitouche L. Dynamic response and damage modelling of glass/epoxy tubular structures: numerical investigation. Composites Part A: Applied Science and Manufacturing 2008; 39:1-12.

[10] Hamitouche L, Tarfaoui M, Vautrin A. Design and test of sandwich T-joint for naval ships. Damage and Fracture Mechanics: Springer 2009. p.131-141.

[11] Tarfaoui M, Hamitouche L. Mode I interlaminar fracture toughness of throughthickness reinforced laminated structures. Advanced Materials Research 2012;423:154- 
165.

[12] Gning P, Tarfaoui M, Davies P, Collombet F. Prediction of damage in composite cylinders after impact. Journal of Composite Materials 2005;39(10):917-928.

[13] Parga-Landa B, Vlegels S, Herandez-Olivares F, Clark S. An analytical study of the effect of slamming pressures on the interlaminar behaviour of composite panels. Composite Structures 1999;46:357-365.

[14] Das K, Batra C. Local water slamming impact on sandwich composite hulls. Journal of Fluids and Structures 2011;27:523-551.

[15] Manganelli P, Wilson P. An experimental investigation of slamming on ocean racing yachts. In: Proceedings of the 15th Chesapeake sailing yacht symposium, Chesapeake Bay, Maryland, USA, 2001.

[16] Santos F, Temarel P, Guedes Soares C. On the limitations of two-and threedimensional linear hydroelasticity analyses applied to a fast patrol boat. Proc. Inst. Mech. Eng.- Part M: J. Eng. Marit. Environ 2009;223:457-478.

[17] Charca S, Shafiq B. Damage assessment due to single slamming of foam core sandwich composites. Journal of Sandwich Structures and Materials 2009;12:97-112.

[18] Charca S, Shafiq B. Repeating slamming of sandwich composite panels on water. Journal of Sandwich Structures and Materials 2009;11:409-424.

[19] Stenius I, Rose A, Kuttenkeuler J. Hydroelastic interaction in panel-water impacts of high-speed craft. Ocean Engineering 2011;38:371- 381.

[20] Stenius I, Rsén A, Battley M, Allen T. Experimantal hydroelastic characterization of slamming loaded marine panels. Ocean Engineering 2013;74:1-15.

[21] Stenius I, Rosén A, Kuttenkeuler J. Explicit FE-modelling of hydroelasticity in panelwater impacts. International Shipbuilding Progress 2007;54:111-127.

[22] Xiao J, Batra R. Delamination in sandwich panels due to local water slamming loads. Journal of Fluids and Structures 2014;48:122-155. 
[23] Guo W, Xue P, Yang J. Nonlinear progressive damage model for composite laminates used for low-velocity impact. Applied Mathematics and Mechanics 2013;34:1145-1154.

[24] Wang S, Wu L, Ma L. Low-velocity impact and residual tensile strength analysis to carbon fiber composite laminates. Materials and Design 2010;31:118-125.

[25] Aquelet N, Souli M. A new ALE formulation for sloshing analysis. Structural Engineering and Mechanics 2003;16:000-000.

[26] Benson D. Computational methods in Lagrangian and Eulerian hydrocodes. Computer Methods in Applied Mechanics and Engineering 1992;99:235-394.

[27] Benson D. Contact in a multi-material Eulerian finite element formulation. Computer Methods in Applied Mechanics and Engineering 2004;193:4277-4298.

[28] Aboshio A, Ye J. Numerical study of the dynamic response of inflatable offshore fender barrier structures using the Coupled Eulerian-Lagrangian discretization technique. Ocean Engineering 2016;112:265-276.

[29] Battley M, Allen T, Pehrson P, Stenius I, Rosen A. Effects of panel stiffness on slamming response of composite hull panels. In ICCM17, Edinburgh, UK, 2009.

[30] Allen T, Battley M. Quantification of hydroelasticity in water impacts of flexible composite hull panels. Ocean Engineering 2015;100:117-125.

[31] Shah O, Tarfaoui M. Effect of adhesive thickness on the Mode I and II strain energy release rates. Comparative study between different approaches for the calculation of Mode I \& II SERR's. Composites Part B: Engineering 2016;96:354-363.

[32] DVN. Hull Structure Design, Fiber Composite and Sandwich Constructions. In Rule for Classification of High speed, Light Craft and Naval Surface Craft,2011. Part 3, Chapter 4.

[33] Shafiq B, Charca S, Just F. Repeated slamming of the foamcore sandwich composite panels on water. In ICCM17 Conference, Edinburgh, UK, July, 2009. 


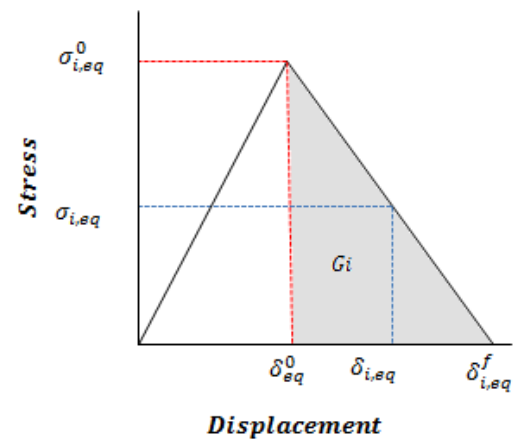

Fig. 1. Typical behavior of material stiffness degradation.

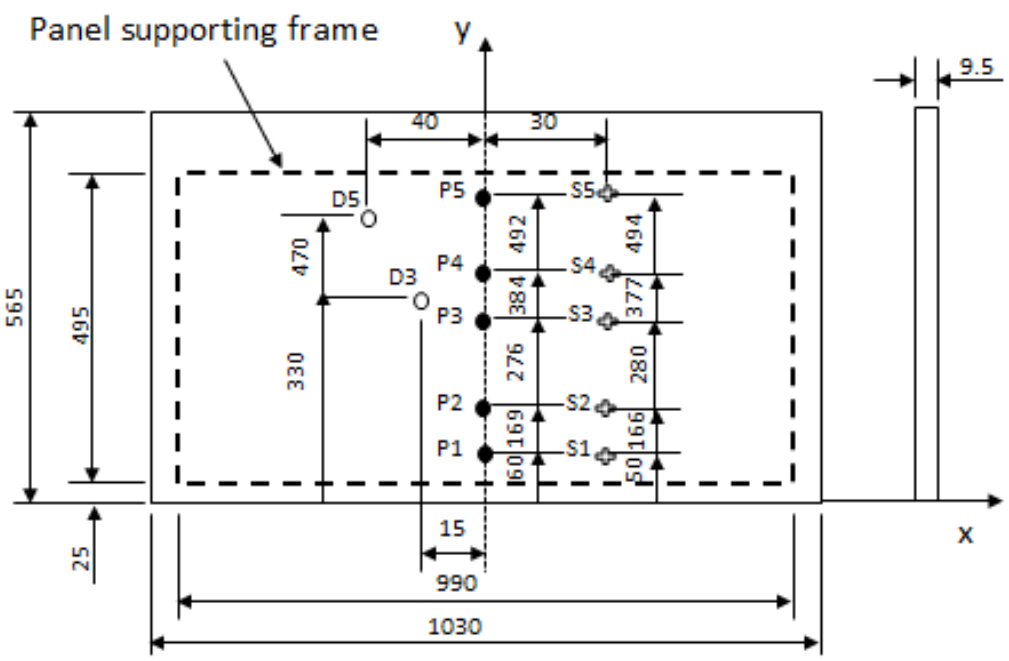

Fig. 2. Panel instrumentations and setup

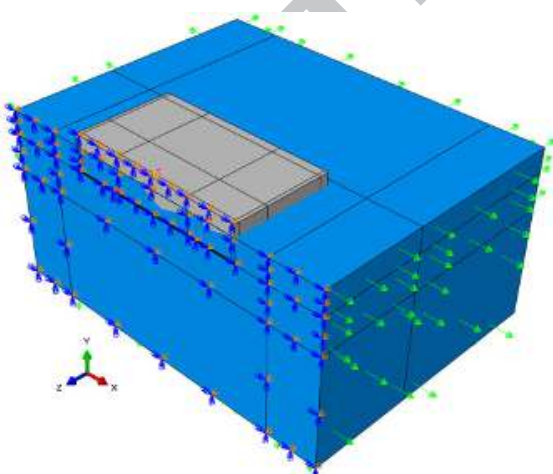

(a)

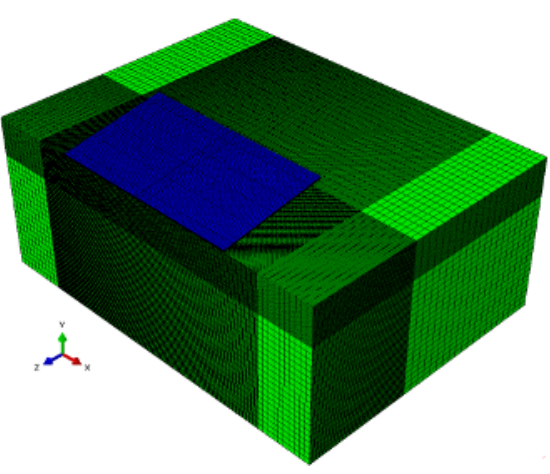

(b)

Fig. 3. Slamming model: (a) boundary conditions, (b) FE mesh. 


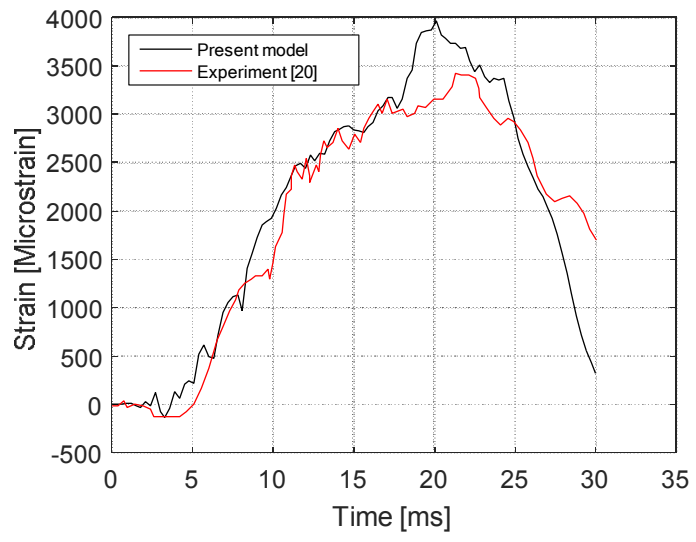

S3

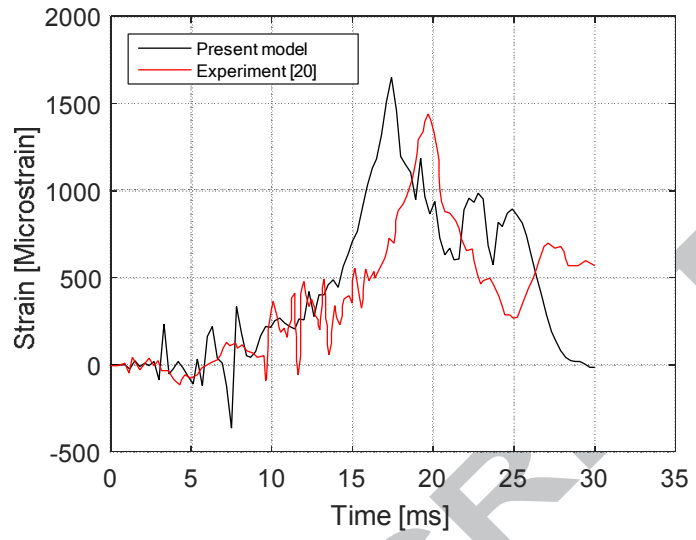

S5

Fig. 4. Comparative of the panel deformation between of the numerical results and experimental data, $\mathrm{V}=4 \mathrm{~m} / \mathrm{s}$
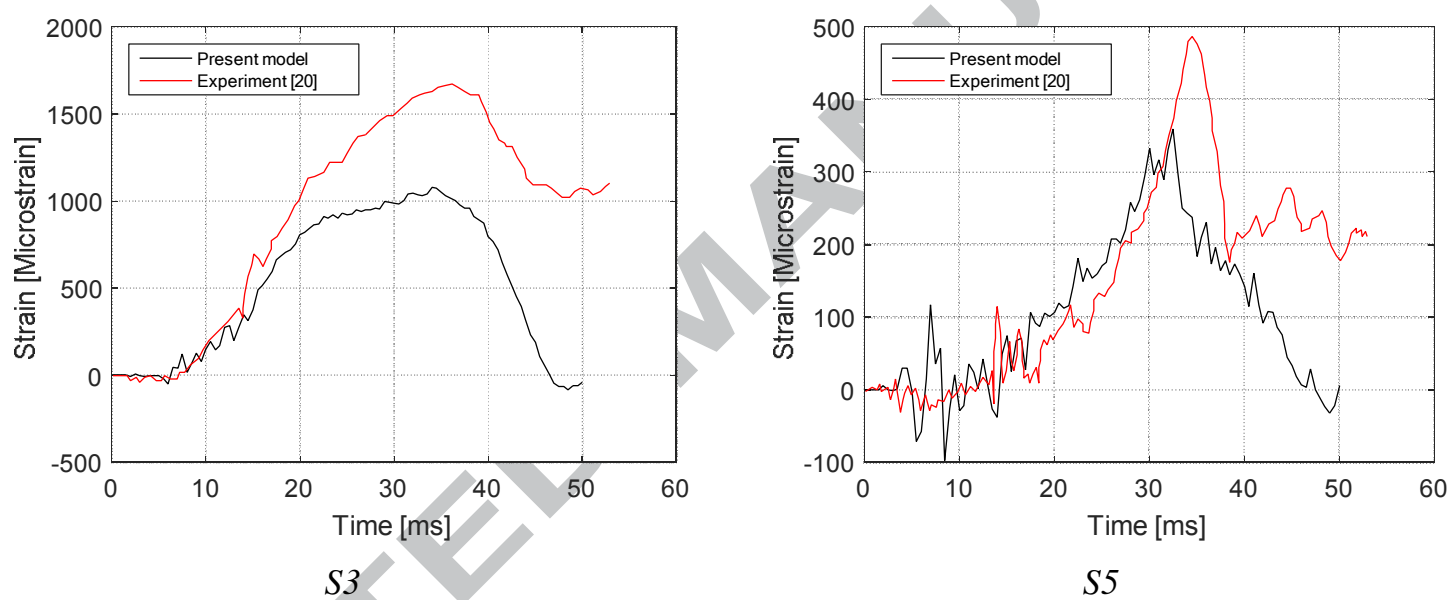

S5

Fig. 5. Comparative of the panel deformation between of the numerical results and experimental data, $\mathrm{V}=2 \mathrm{~m} / \mathrm{s}$.

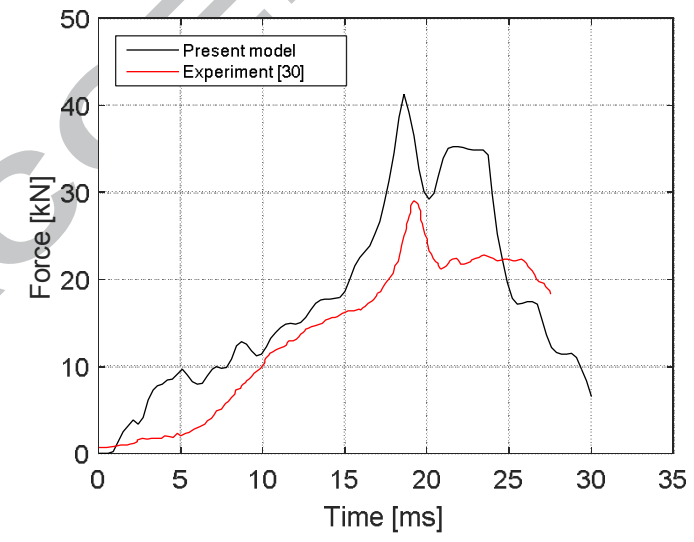

Force-V-4

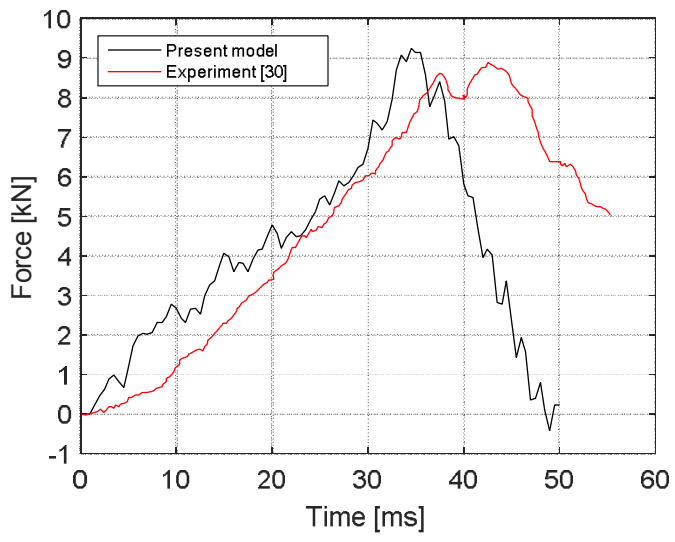

Force- $V-2$

Fig. 6. Comparative of the hydrodynamic force between of the numerical results and experimental data. 




ODB: validation $\mathrm{t} 9$ is relocity 4 maberlal2.odb abaqus/Expliclt 3DEXPERIEHCE R2016x Step: Step-1 Primary Var: $S$, $S 11$,

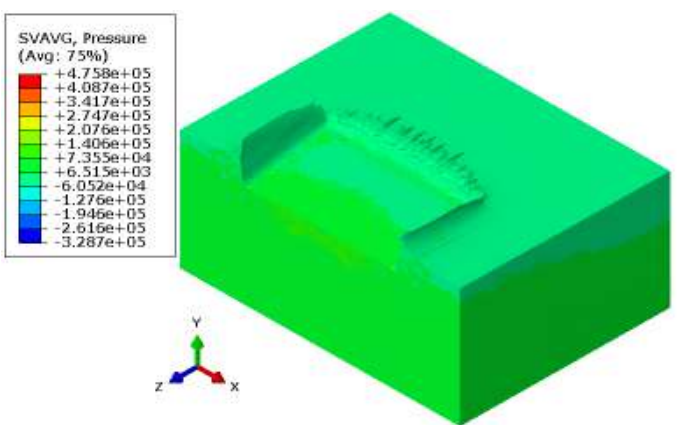

ODB: validation-t-9-5-velocity-4-material2,odb Abaqus/Explicit 3DEXPERIENCE R2016x Step: Step- 1
IIcrement $122510:$ Step Time $=2.8800 \mathrm{E}-02$

Primory Var: SVAVG, Pressure Deformed Var: U Deformation Scale factor: +1.000 e +00

Fig. 7. Snapshot of the model after impact

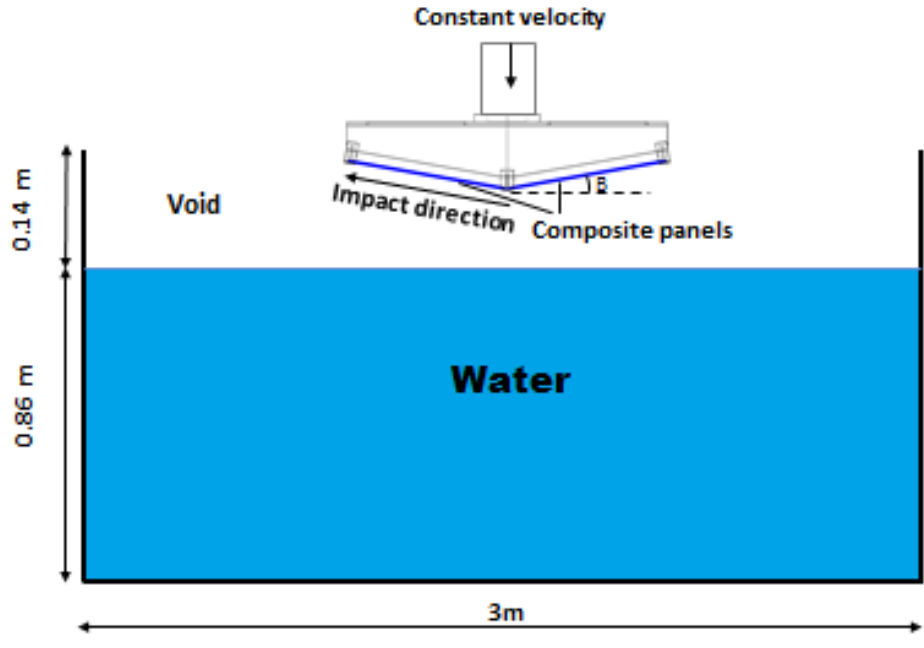

(a)

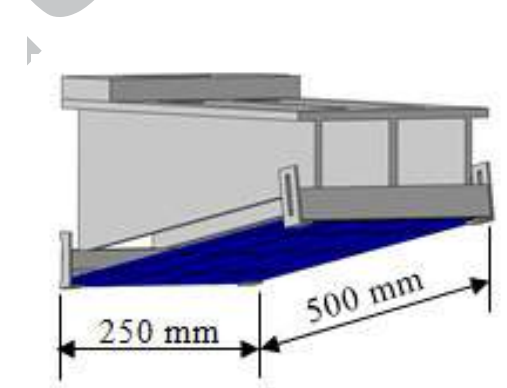

(b)

Fig. 8. (a) Schematic representation of full model and (b) CAE impactor model.

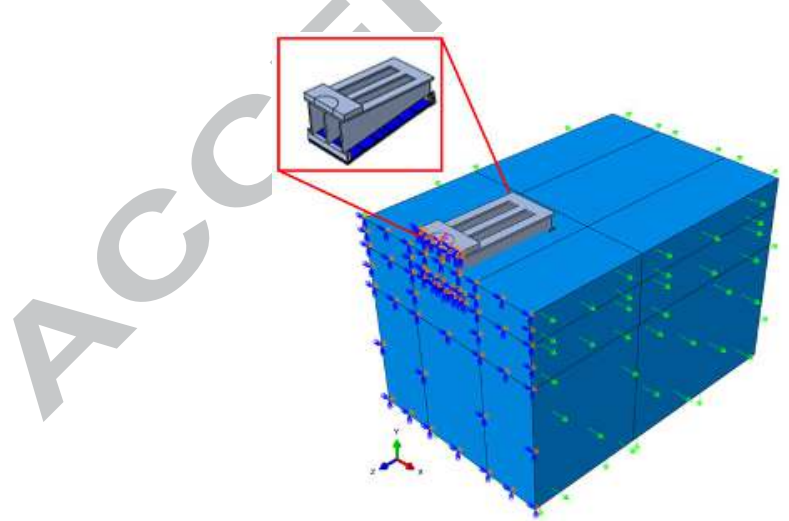

(a)

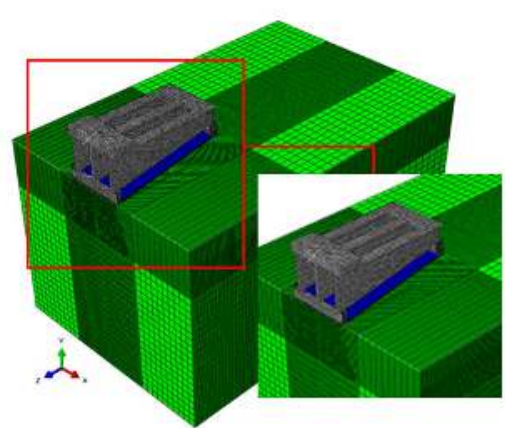

(b)

Fig.9. Three-dimensional representation of half slamming model: (a) boundary conditions, (b) FE mesh. 


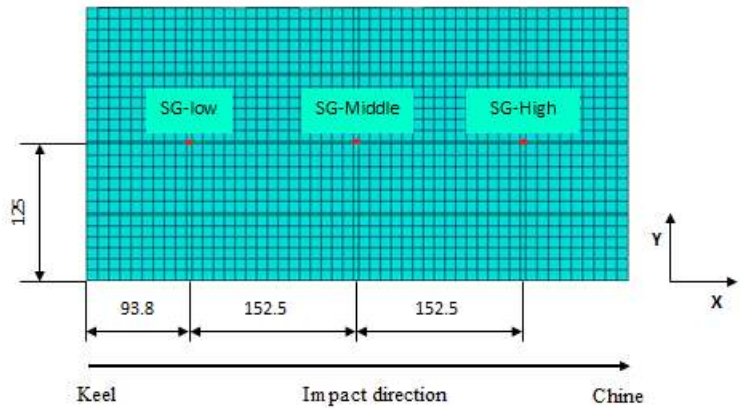

(a)

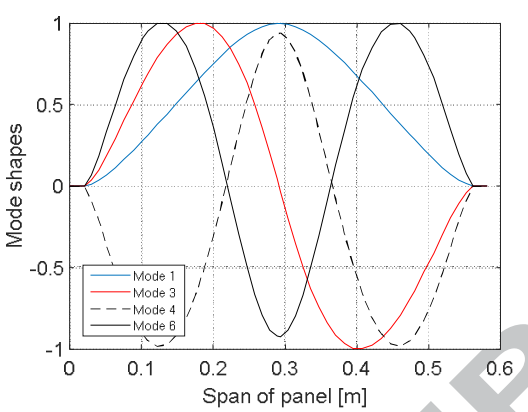

(b)

Fig. 10. Panel setup (a) FE mesh of the laminate composite panel and zone of implantation of strain gauges (SG) (b) Mode shapes of the dry panels.

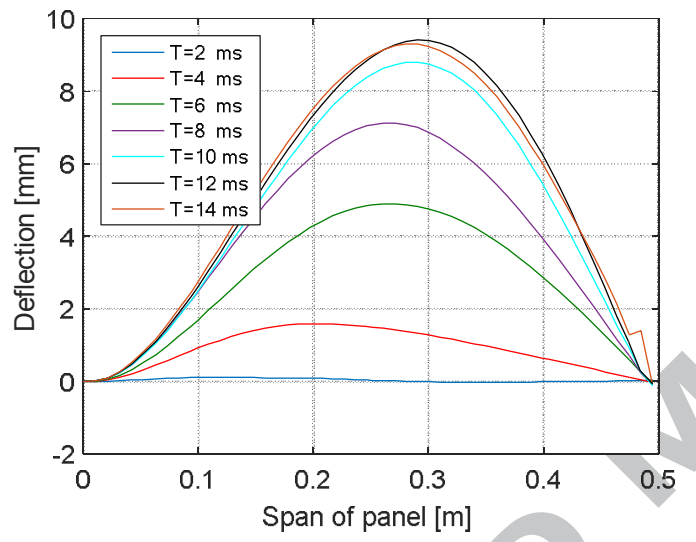

(a) Panel deflexion

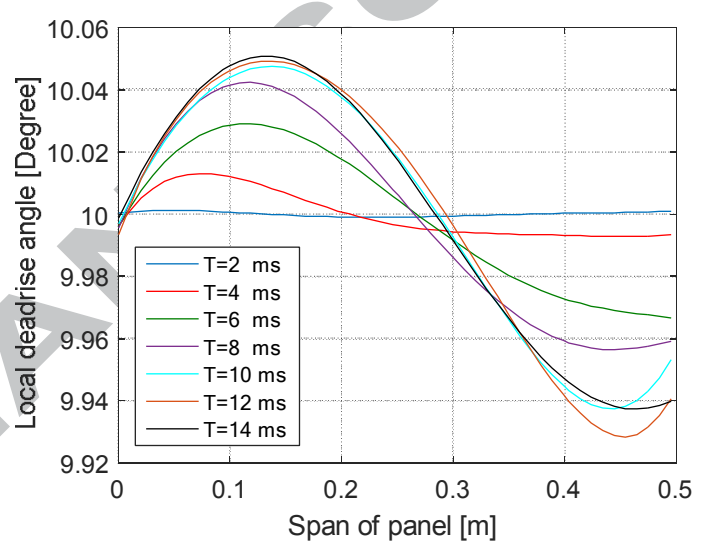

(b) Local deadrise angle

Fig. 11. Histories of kinematic effect of semi-flexible panel, V=6 m/s.

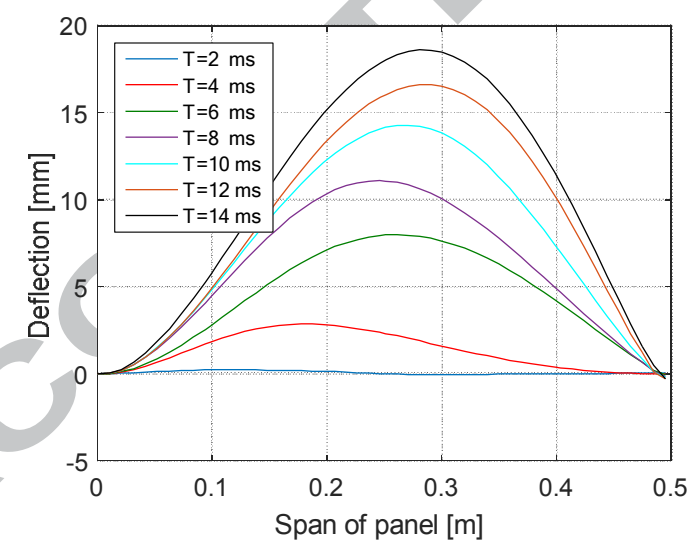

(a) Panel deflexion

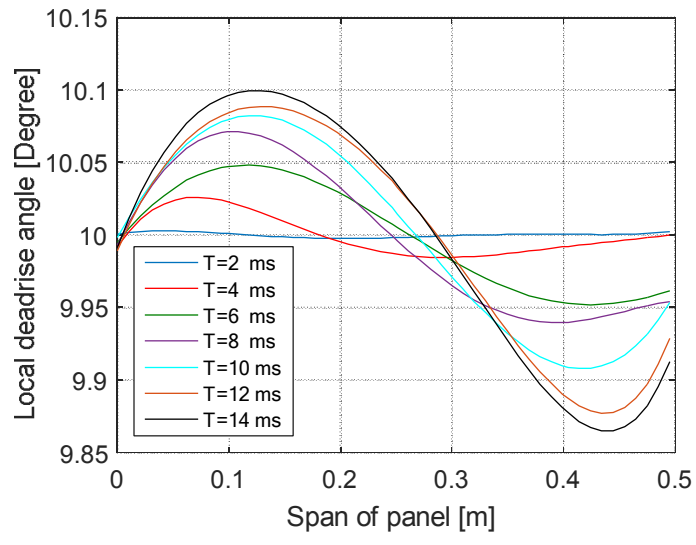

(b) Local deadrise angle

Fig. 12. Histories of kinematic effect of flexible panel, $V=6 \mathrm{~m} / \mathrm{s}$. 


\section{ACCEPTED MANUSCRIPT}

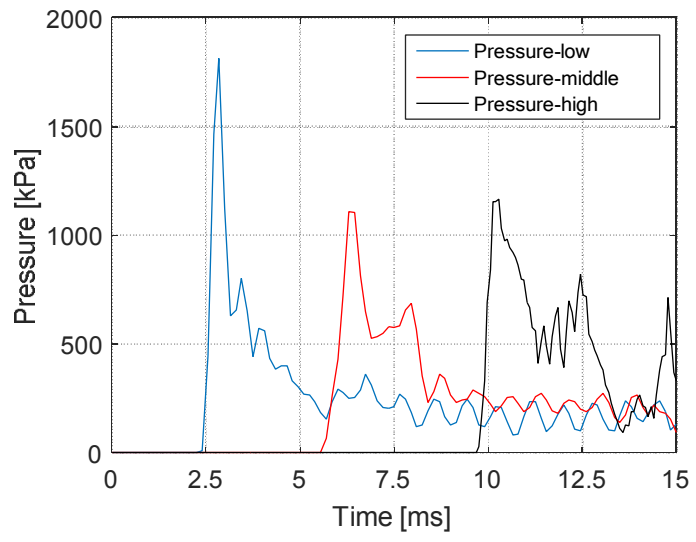

(a) Rigid body

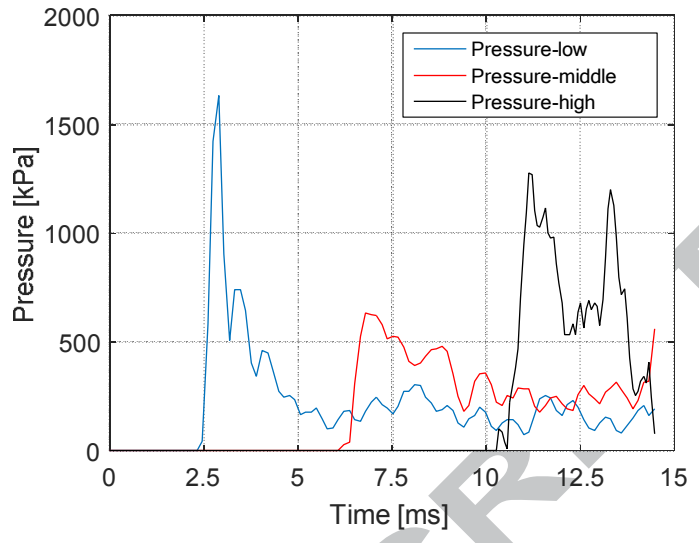

(b) Semi-flexible

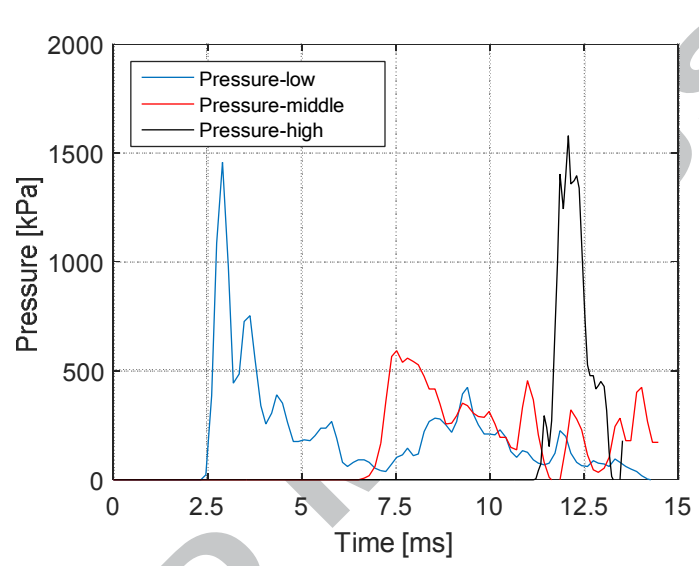

(c) flexible

Fig. 13. Pressure time histories for $V=6 \mathrm{~m} / \mathrm{s}$. 

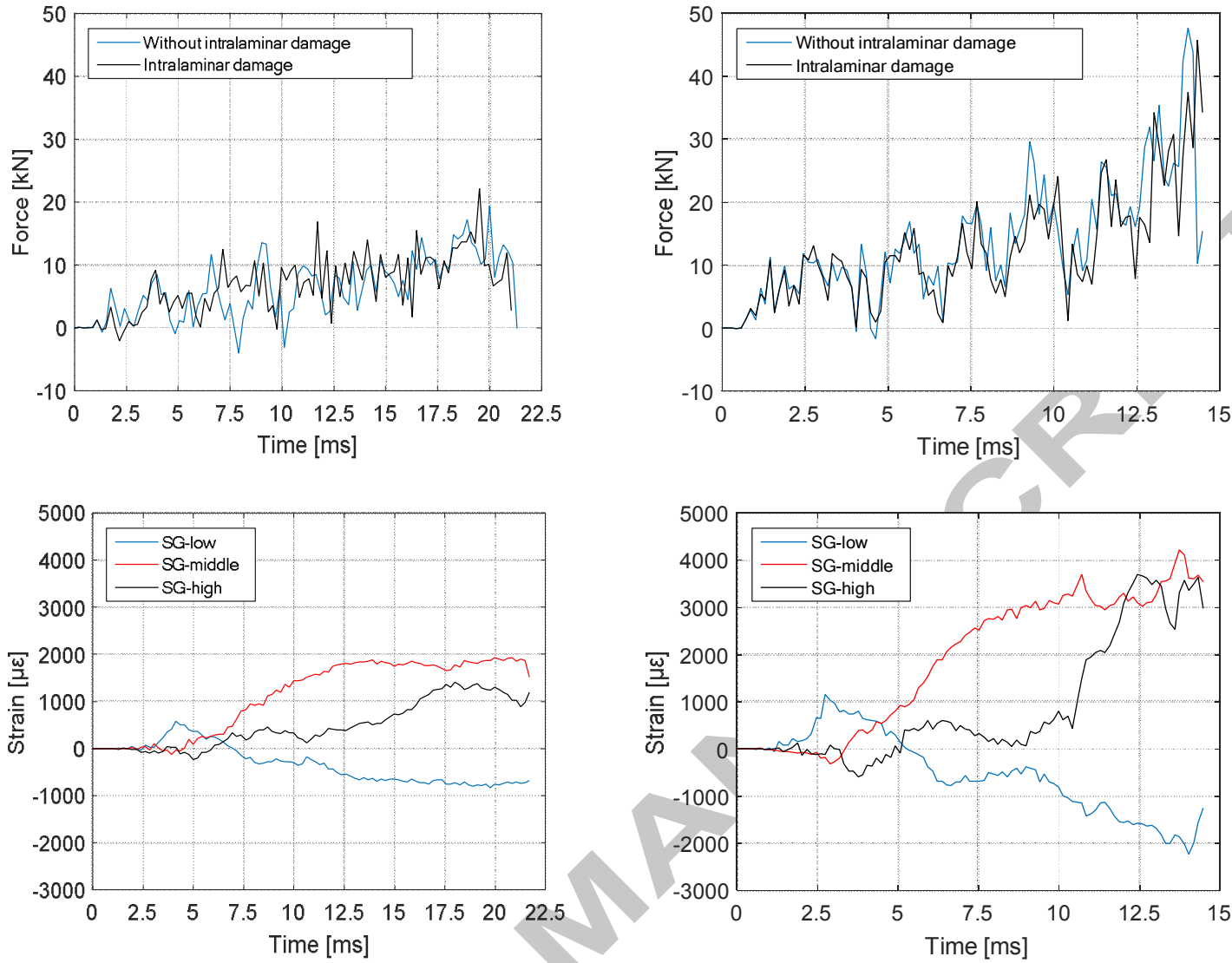

(a) $V=4 \mathrm{~m} / \mathrm{s}$

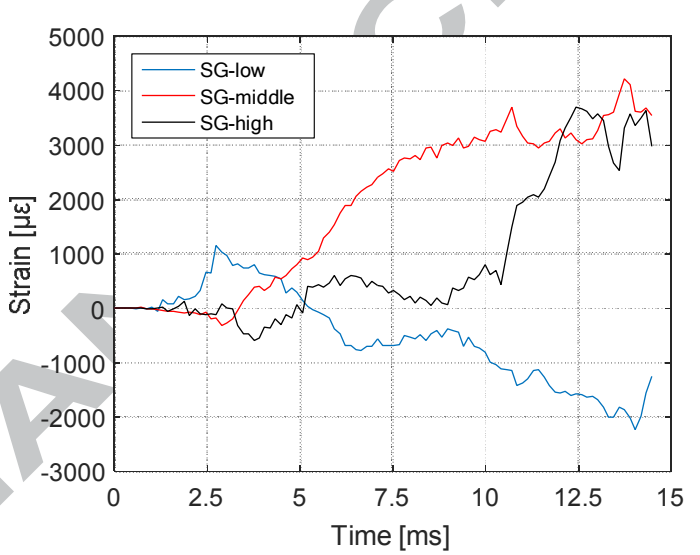

(b) $V=6 \mathrm{~m} / \mathrm{s}$

Fig. 14. Slamming force and the local strain of the flexible panels.
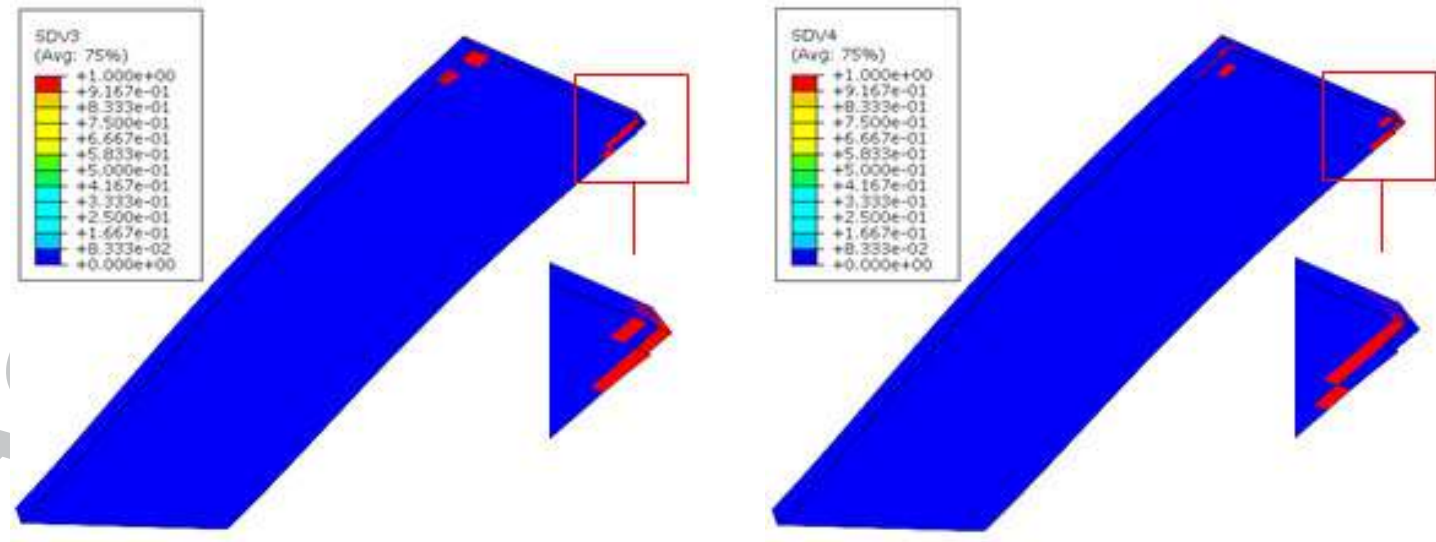

(a) $V=6 \mathrm{~m} / \mathrm{s}$ 

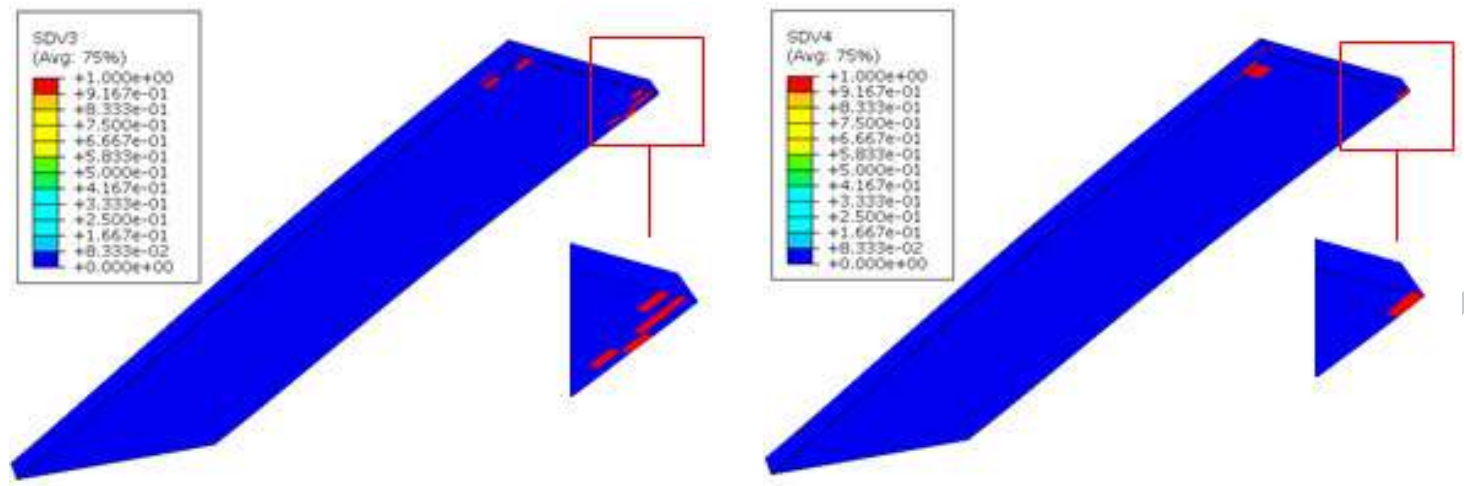

(b) $V=4 \mathrm{~m} / \mathrm{s}$

Fig. 15. Damage for semi-flexible laminate, matrix in tension (SDV3) and compression (SDV4).
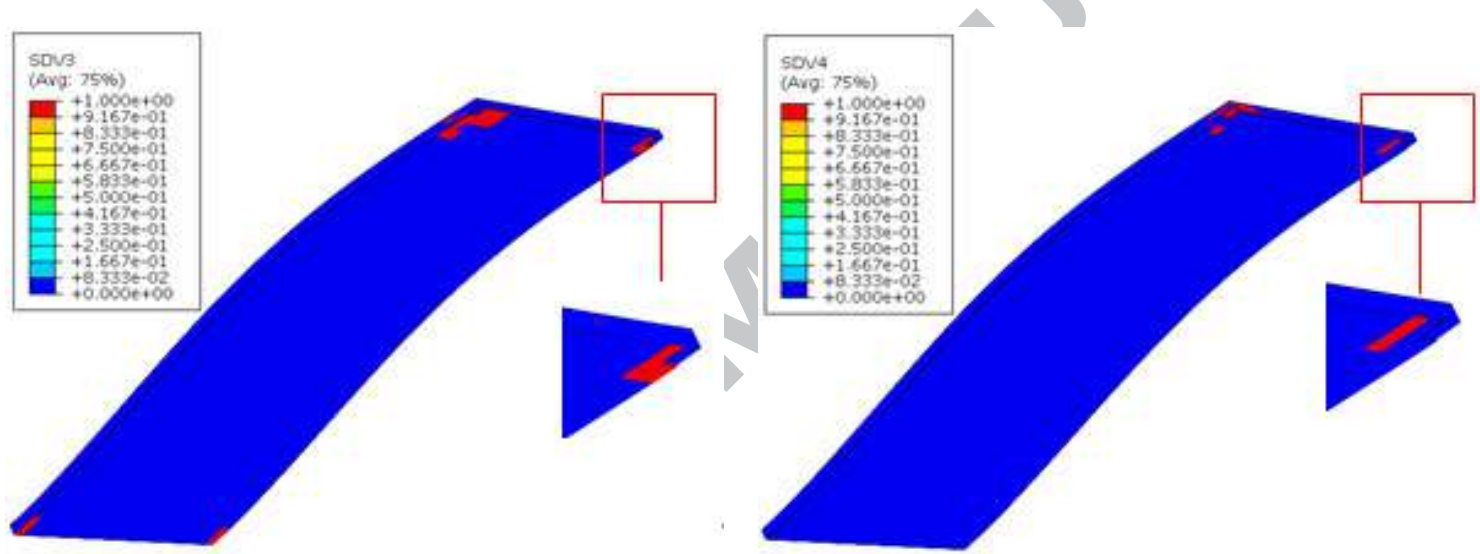

(a) $V=6 \mathrm{~m} / \mathrm{s}$
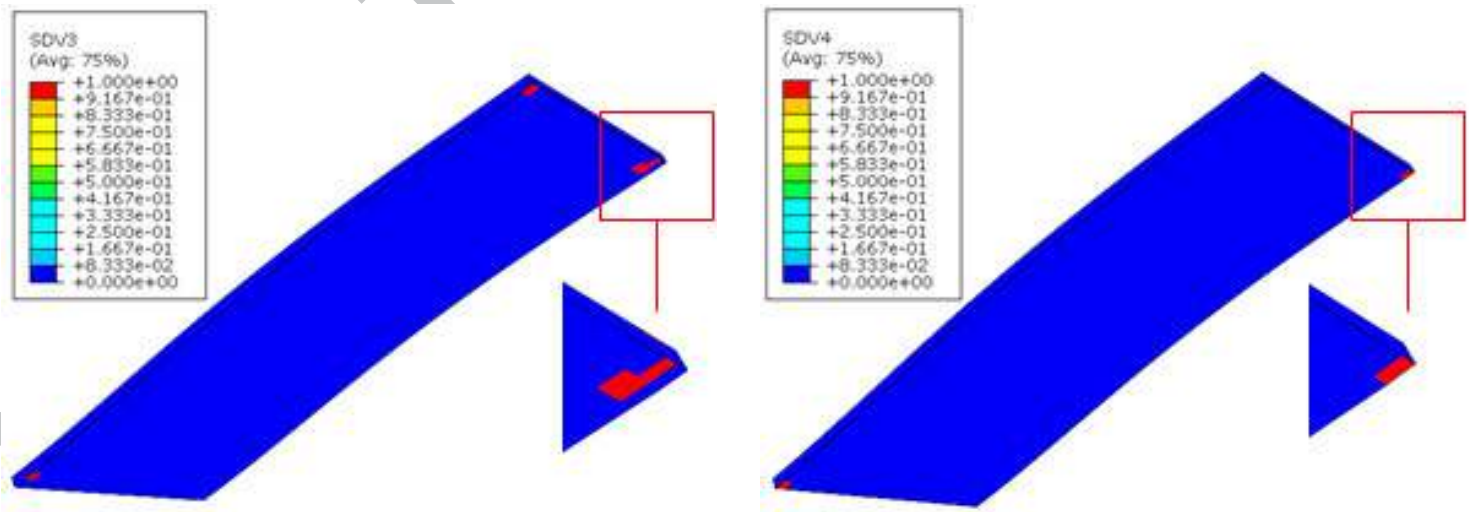

(b) $V=4 \mathrm{~m} / \mathrm{s}$

Fig. 16. Damage for flexible laminate, matrix in tension (SDV3) and compression (SDV4). 

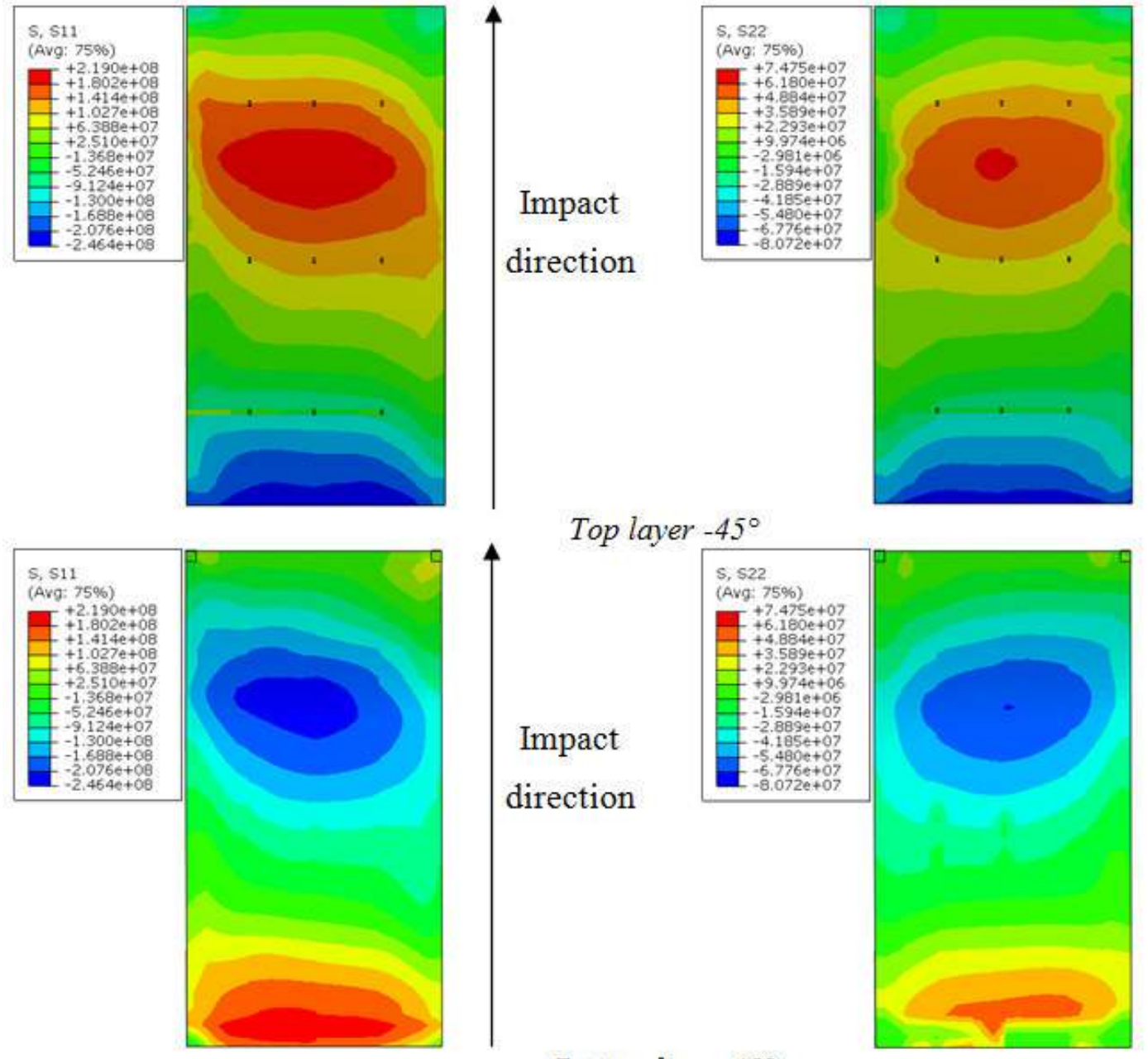

Bottom layer $45^{\circ}$

Fig. 17. Stress distribution in semi-flexible panel, V=10 m/s. 


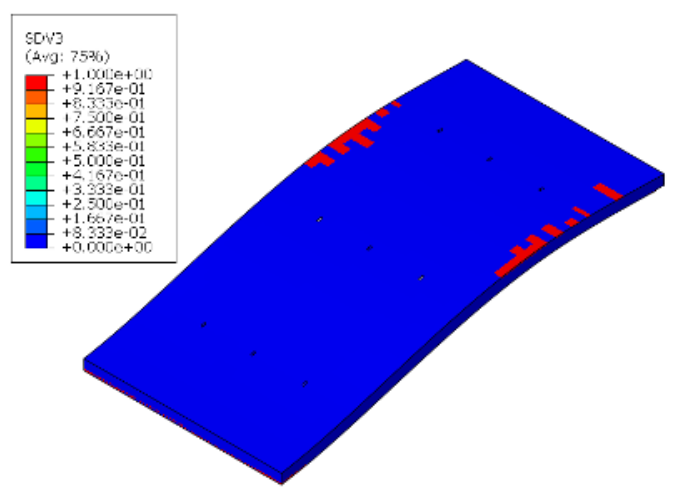

Top layer (matrix tension)

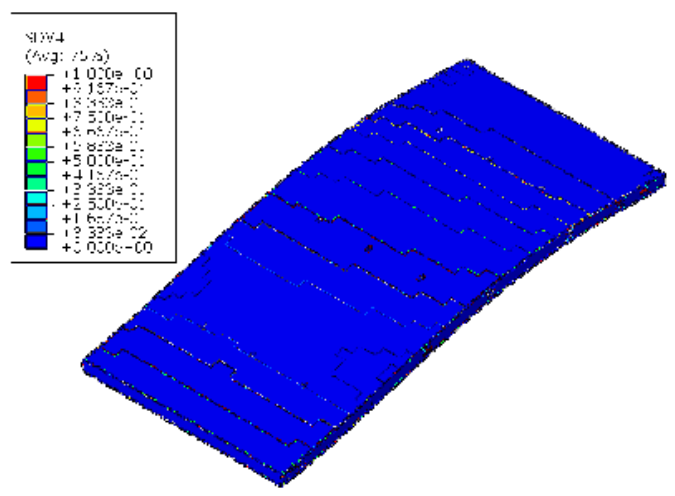

Top layer (matrix compression)

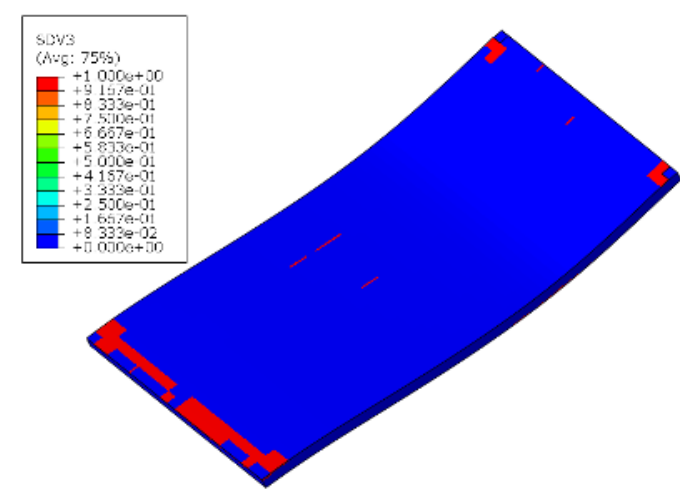

Bottom layer (matrix tension)

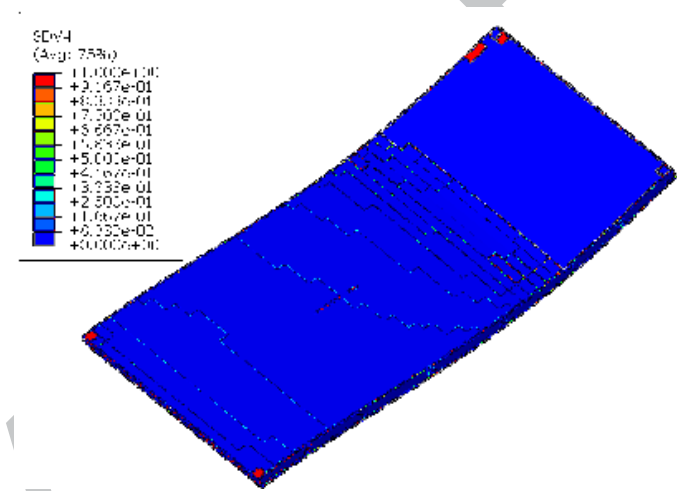

Bottom layer (matrix compression)

Fig. 18. Damage in semi-flexible panel, V=10 m/s.

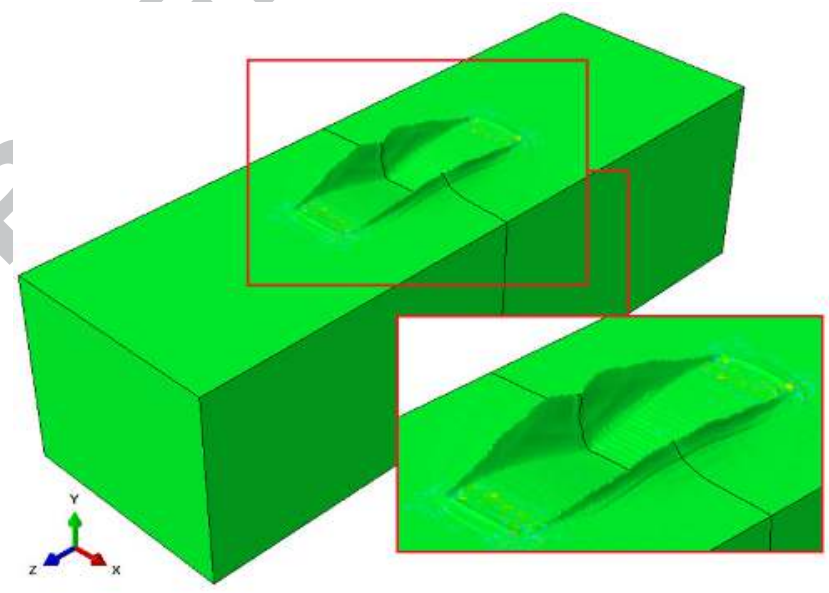

Fig. 19. Signature of the slamming problem: impacted zone by composite panels and formation of the water jet. 

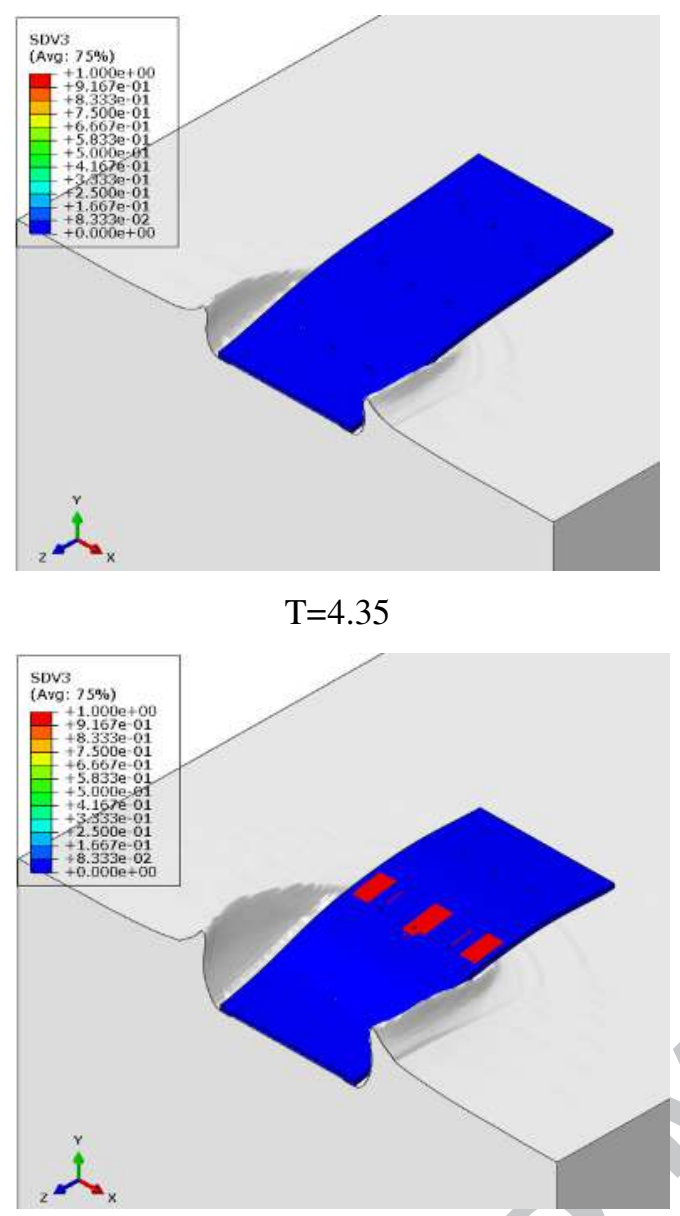

$\mathrm{T}=6.525$

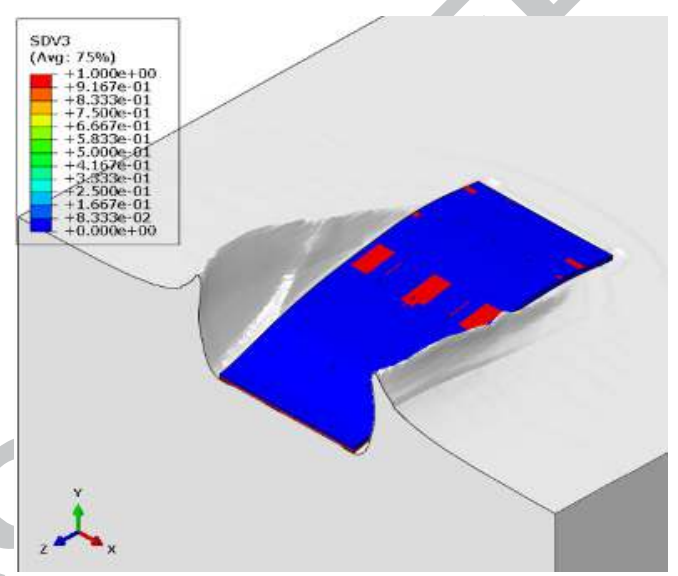

$\mathrm{T}=8.7 \mathrm{~ms}$

(a)
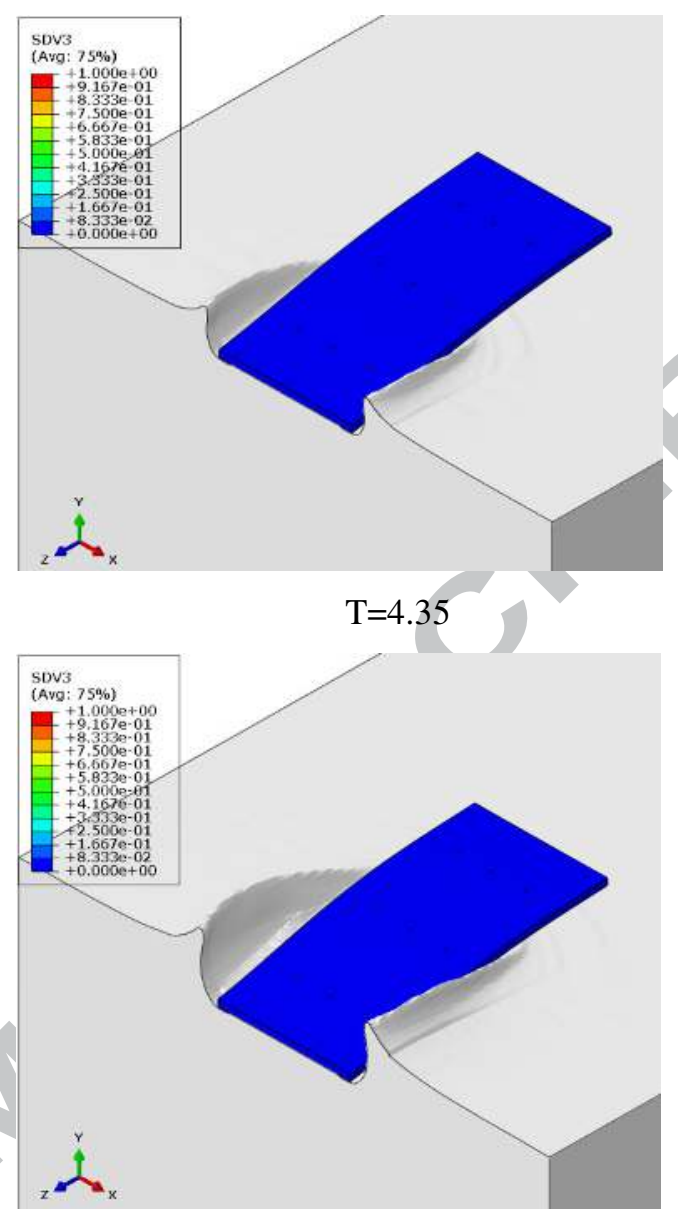

$\mathrm{T}=6.525$

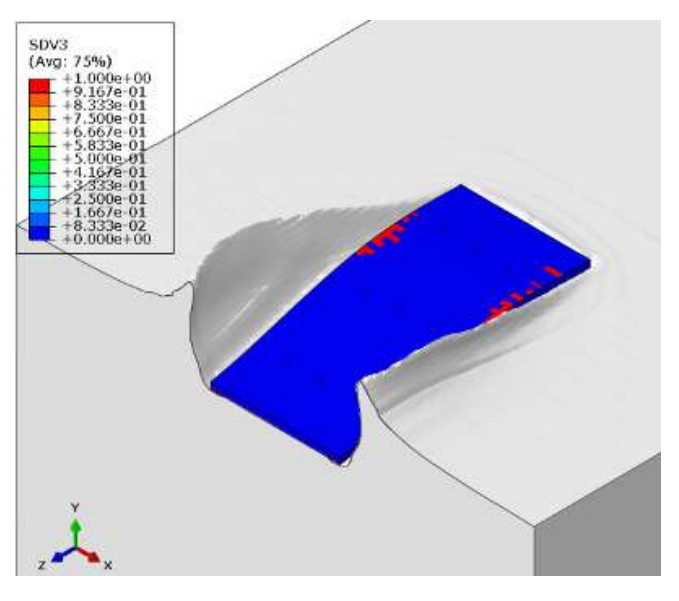

$\mathrm{T}=8.7 \mathrm{~ms}$

(b)

Fig. 20. Time capture of damaged panels under slamming impact and formation of the fluid jet for: (a) flexible panel and (b) semi flexible panel. 
Table 1. Hashin Failure criteria

Fiber Tensile Failure

$$
f_{f t}=\left(\frac{\sigma_{11}}{X_{t}}\right)^{2} \geq 1
$$

$$
\left(\sigma_{11} \geq 0\right)
$$

Fiber Compression

Failure

$$
f_{f c}=\left(\frac{\sigma_{11}}{X_{c}}\right)^{2} \geq 1
$$

$\left(\sigma_{11}<0\right)$

Matrix Tensile Failure $\quad f_{m t}=\frac{\left(\sigma_{22}+\sigma_{33}\right)^{2}}{Y_{t}^{2}}+\frac{{\sigma_{23}}^{2}-\sigma_{22} \sigma_{33}}{S_{23}^{2}}+\left(\frac{\sigma_{12}}{S_{12}}\right)^{2}+\left(\frac{\sigma_{13}}{S_{13}}\right)^{2}$

$$
\left(\sigma_{22}+\sigma_{33}\right) \geq 0 \quad \geq 1
$$

Matrix Compression $\quad f_{m c}=\frac{1}{Y_{c}}\left(\left(\frac{Y_{c}}{2 S_{23}}\right)^{2}-1\right)\left(\sigma_{22}+\sigma_{33}\right)+\frac{\left(\sigma_{22}+\sigma_{33}\right)^{2}}{4 S_{23}{ }^{2}}$

Failure

$$
\left(\sigma_{22}+\sigma_{33}\right)<0 \quad+\frac{\sigma_{23}^{2}-\sigma_{22} \sigma_{33}}{S_{23}^{2}}+\left(\frac{\sigma_{12}}{S_{12}}\right)^{2}+\left(\frac{\sigma_{13}}{S_{13}}\right)^{2} \geq 1
$$

Table 2. Mie-Gruneisen EOS Parameters

\begin{tabular}{ccccc}
\hline$C_{0}(\mathrm{~m} / \mathrm{sec})$ & $\mu(-)$ & $s(-)$ & $\Gamma_{0}(-)$ & $\rho\left(\mathrm{kg} / \mathrm{m}^{3}\right)$ \\
\hline 1420 & 0.001 & 0 & 0 & 1000 \\
\hline
\end{tabular}


Table 3. Properties of glass-fiber vinylester composite panels

\begin{tabular}{|c|c|c|c|c|c|c|c|c|}
\hline \multicolumn{3}{|c|}{ Elastic moduli $(\mathrm{GPa})$} & \multicolumn{3}{|c|}{ Position ratios (-) } & \multicolumn{3}{|c|}{ Shear moduli (GPa) } \\
\hline$E_{11}$ & $E_{22}$ & $E_{33}$ & $v_{12}$ & $v_{13}$ & $v_{23}$ & $G_{12}$ & $G_{13}$ & $G_{23}$ \\
\hline 48.16 & 11.21 & 11.21 & 0.274 & 0.274 & 0.096 & 4.42 & 4.42 & 9 \\
\hline \multicolumn{6}{|c|}{ Ultimate tensile and compression strengths (MPa) } & \multicolumn{3}{|c|}{ Ultimate Shear strengths (MPa) } \\
\hline$X_{t}$ & $X_{c}$ & $Y_{t}$ & $Y_{c}$ & $Z_{t}$ & $Z_{c}$ & $S_{12}$ & $S_{13}$ & $S_{23}$ \\
\hline 1021 & 978 & 250 & 300 & 250 & 300 & 70 & 70 & 30 \\
\hline \multicolumn{9}{|c|}{ Intralaminar Fracture energy $\left(\mathrm{J} / \mathrm{m}^{2}\right)$} \\
\hline \multicolumn{4}{|c|}{$G_{f t}$} & $G_{f c}$ & $G_{m t}$ & $G_{m c}$ & & \\
\hline \multicolumn{4}{|c|}{1000} & 1000 & 500 & 500 & & \\
\hline
\end{tabular}

